\title{
Impacted Bullet in the Sphenoid Sinus: A Case Report
}

\author{
B. Vageesh Padiyar Ankur Vats Akanksha Dhiman A.K. Rai \\ Department of Otorhinolaryngology, Dr. Ram Manohar Lohia Hospital, New Delhi, India
}

\section{Keywords}

Sphenoid sinus - Bullet $\cdot$ Endoscope

\begin{abstract}
A bullet encountered as a foreign body in the sphenoid sinus is a rare occurrence. We report a case of a bullet impacted in the sphenoid sinus following a firing assault from point blank range. The bullet was safely removed with the assistance of an endoscope preserving the structures around the sphenoid sinus. Adequate knowledge of the anatomical variations with regard to the sphenoid sinus is essential to ensure safe removal of foreign bodies, thereby avoiding catastrophic complications. We believe that endoscopic foreign body removal should be advocated more often, rather than open approaches, for foreign bodies impacted beyond the sphenoid sinus involving the anterior skull base.
\end{abstract}

\footnotetext{
(C) 2019 The Author(s)

Published by S. Karger AG, Basel
}

\section{Background}

Foreign bodies in the nasal cavity are more common in children than in adults [1]. Foreign bodies most commonly get lodged in the maxilla and frontal sinuses compared to the ethmoids and sphenoid sinuses [2,3]. Foreign bodies reach the sphenoid sinus either through the orbit or through the nasal cavity. Proximity of the sphe-

\begin{tabular}{ll}
\hline KARGER & $\begin{array}{l}\text { (c) } 2019 \text { The Author(s) } \\
\text { Published by S. Karger AG, Basel }\end{array}$ \\
E-Mail karger@karger.com & $\begin{array}{l}\text { This article is licensed under the Creative Commons Attribution- } \\
\text { NonCommercial-NoDerivatives 4.0 International License (CC BY- } \\
\text { NC-ND) (http://www.karger.com/Services/OpenAccessLicense). } \\
\text { Usage and distribution for commercial purposes as well as any dis- } \\
\text { tribution of modified material requires written permission. }\end{array}$
\end{tabular}

noid sinus to vital structures such as the optic nerve and internal carotid artery may render life-threatening complications. Removal of such foreign bodies requires good preoperative planning, sound anatomy, and knowledge of variations of the sphenoid sinus. Endonasal endoscopic removal of such foreign bodies is preferred considering effective magnification and illumination. We present a case of an impacted bullet in the sphenoid sinus following a firing assault from point blank range.

\section{Case Report}

A 35-year-old male patient was referred to us from the emergency department for an alleged history of gunshot injury from point blank range. The patient was unconscious on arrival to the emergency department and his vitals were stabilized over 2 days. Primary examination of the patient showed the presence of a $3 \times$ $3 \mathrm{~cm}$ defect over the forehead with exposed bone fragments within the defect (Fig. 1).

Examination of the patient revealed dilated pupils, absent papillary reflexes, and no perception of light in the right eye. The left eye examination was normal. Extraocular movements were normal in all direction in both eyes. Routine investigations including ultrasonography of the abdomen done in FAST (focused assessment with sonography in trauma) showed no significant findings. Computerized tomography (CT) scan of the brain showed hemorrhagic contusions involving the bilateral basifrontal cortex with subdural hemorrhage seen over the right frontal convexities extending into the anterior falx cerebri. X-ray and CT of the nose and paranasal sinuses revealed a metallic artifact seen in the right sphenoid sinus impinging on the right optic canal with metallic pellets in the ethmoid sinus (Fig. 2, 3).
Dr. B. Vageesh Padiyar

Department of Otorhinolaryngology, Dr Ram Manohar Lohia Hospital Baba Karak Singh Marg

New Delhi 110001 (India)

E-Mail gpadiyar@hotmail.com 


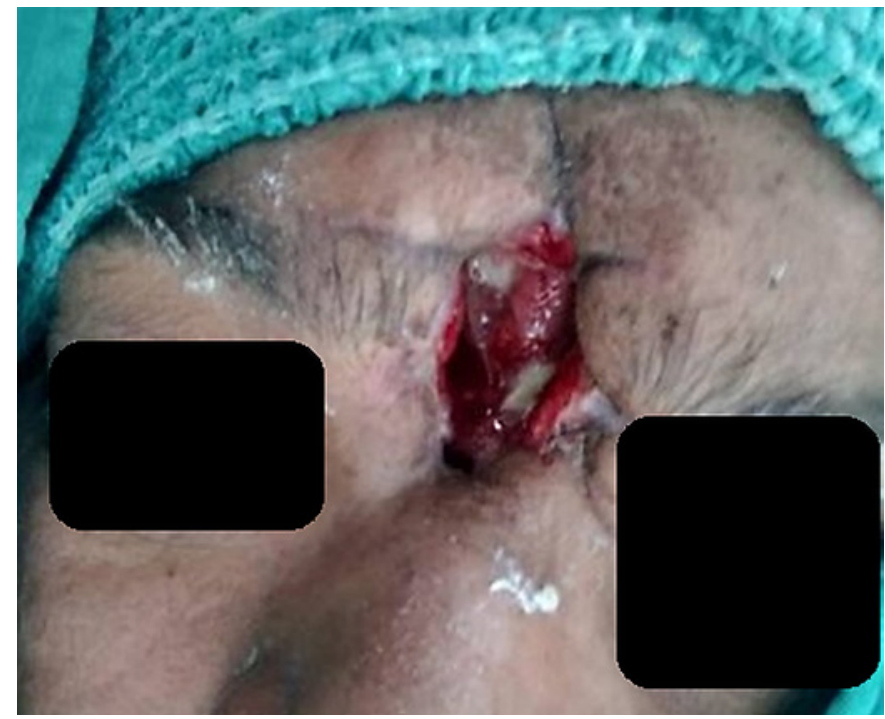

Fig. 1. Preoperative picture showing the defect following bullet injury.

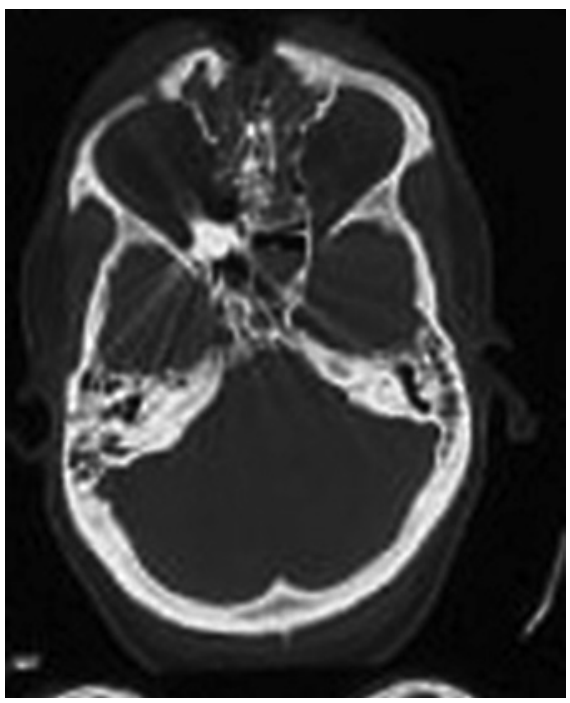

Fig. 3. CT scan showing the location of the bullet impinging on the right optic canal.

Three days following injury, the patient underwent endoscopic removal of the bullet lodged in the posterior ethmoids and anterolateral wall of the sphenoid sinus (Fig. 4). Subsequently, he underwent $3 \mathrm{D}$ reconstruction $\mathrm{CT}$ of the head and was planned for reconstruction of the defect with a left forehead flap and cancellous bone graft. The patient was followed up postoperatively after 6 months of reconstruction with a satisfactory esthetic outcome and complete resolution of visual acuity.

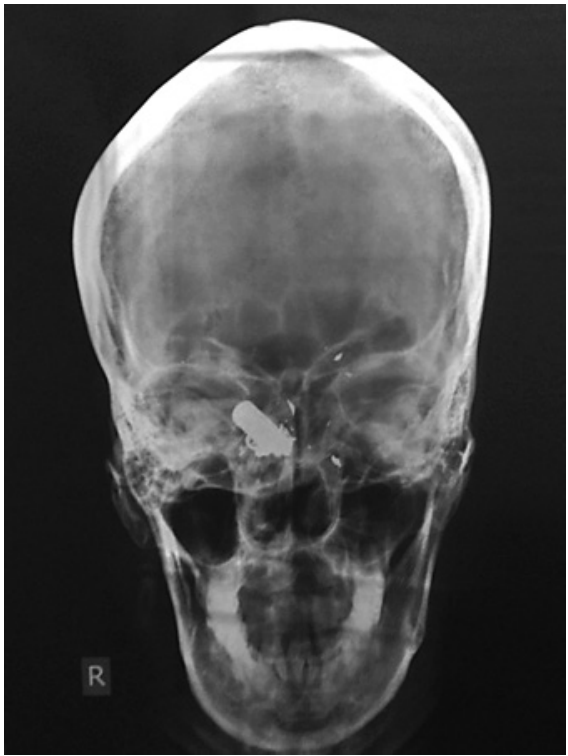

Fig. 2. X-ray showing the bullet lodged in the sphenoid sinus.

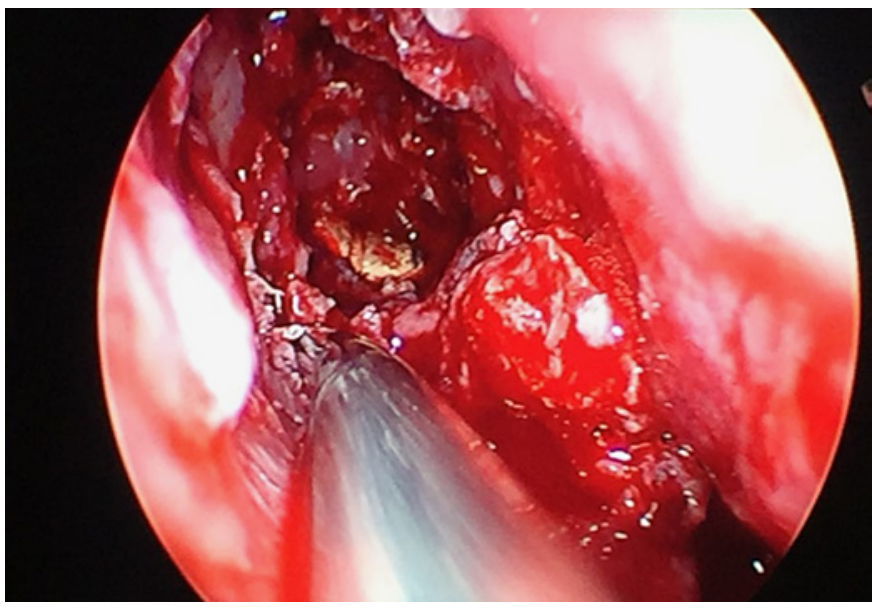

Fig. 4. Intraoperative endoscopic picture of the bullet.

\section{Discussion}

Foreign bodies rarely involve the sphenoid sinus, with more common involvement of the maxilla and frontal sinuses. The most common route of entry is usually through the orbit or the nasal cavity. CT scans play an important role in assessing the relation of the foreign body with the 
surrounding structures. Digital subtraction angiography has been used to rule out vascular injury before attempting foreign body removal [4]. Removal of such foreign bodies warrants urgent removal in view of intracranial migration, systemic lead poisoning, and its associated complications [5].

All foreign bodies have a propensity to act as a source and nidus of infection at the site of lodgement. With particular regard to the sphenoid sinus, considering its close proximity to the optic nerve, cavernous sinus and its contents, the associated foreign body can lead to catastrophic complications. Our patient was lucky, not having any associated complications and undergoing an uneventful removal procedure.

The best surgical approach to the sphenoid sinus in today's era remains endoscopic, owing to its far superior illumination, magnification, and cosmetic outcome. In addition, it facilitates simultaneous repair of the skull base defects caused by the foreign body [6-8]. Open approaches may be required for the removal of foreign bodies involving the spheno-ethmoidal region in rare circumstances $[9,10]$.

\section{Conclusion}

Sphenoid sinus foreign bodies are rarely encountered by the otolaryngologist. Endonasal endoscopic approach proves an effective and safe technique for the removal of these foreign bodies and repair of the possible skull base defect. A thorough knowledge of the anatomical variations involving the sphenoid sinus remains pivotal in ensuring a safe removal and avoiding possible catastrophic complications.

\section{Statement of Ethics}

The research was conducted ethically in accordance with the World Medical Association Declaration of Helsinki. The subject gave written informed consent to publish his case (including publication of images).

\section{Disclosure Statement}

The authors have no conflicts of interest to declare.

\section{Funding Sources}

No funding was received for this study.

\section{References}

1 Alsarraf R, Bailet JW. Self-inserted sphenoid sinus foreign bodies. Arch Otolaryngol Head Neck Surg. 1998 Sep;124(9):1018-20.

2 Dimitriou C, Karavelis A, Triaridis K, Antoniadis $\mathrm{C}$. Foreign body in the sphenoid sinus. J Craniomaxillofac Surg. 1992 Jul;20(5):2289.

3 O'Connell JE, Turner NO, Pahor AL. Air gun pellets in the sinuses. J Laryngol Otol. 1995 Nov;109(11):1097-100.

4 Yıldırım AE, Divanlığlu D, Çetinalp NE, Ekici I, Dalgıç A, Belen AD. Endoscopic endonasal removal of a sphenoidal sinus foreign body extending into the intracranial space. Ulus Travma Acil Cerrahi Derg. 2014 Mar; 20(2):139-42.
5 Futch C. Lead intoxication from a bullet lodged in sphenoid sinus and surgical removal of the nidus. JAMA. 1943;121(8):580-2.

6 Bhattacharyya N, Wenokur RK. Endoscopic management of a chronic ethmoid and sphenoid sinus foreign body. Otolaryngol Head Neck Surg. 1998 May;118(5):687-90.

7 Kitajiri S, Tabuchi K, Hiraumi H. Transnasal bamboo foreign body lodged in the sphenoid sinus. Auris Nasus Larynx. 2001 Nov;28(4): $365-7$.
8 Liu Z, Lin Y, Zhang L, Yang C, Shen SG, Wang $X$. Endoscopic-assisted navigation-guided removal of long-standing metallic foreign body near to the sphenoid. J Craniofac Surg. 2015 Mar;26(2):e122-4.

9 Kayikçioğlu A, Karamüsel S, Mavili E, Erk Y, Benli K. Intrasphenoidal migration of a premaxillary Kirschner wire. Cleft Palate Craniofac J. 2000 Mar;37(2):209-11.

10 Sharma R, Minhas R, Mohindroo N. An unusual foreign body in the paranasal sinuses. Indian J Otolaryngol Head Neck Surg. 2008 Mar;60(1):88-90. 